\title{
A Soilless Verticillium Wilt Assay Using an Early Flowering Lettuce Line
}

\author{
Steven J. Klosterman and Ryan J. Hayes, United States Department of Agriculture-Agricultural Research Service, \\ 1636 E. Alisal St. Salinas, CA 93905
}

\begin{abstract}
Klosterman, S. J., and Hayes, R. J. 2009. A soilless Verticillium wilt assay using an early flowering lettuce line. Plant Dis. 93:691-698.

A soilless growth chamber assay was evaluated for rapid assessment of Verticillium wilt on lettuce (Lactuca sativa). Seedlings of the early flowering Plant Introduction (PI) 251246 were inoculated in tubes with conidial suspensions of isolates of Verticillium dahliae from lettuce or cauliflower. PI 251246 developed significant leaf and root symptoms by 21 days following inoculation with isolates of race 1 and race 2 from lettuce, but not following inoculation with an isolate from cauliflower. In contrast, leaf symptoms on the cultivar La Brillante and root symptoms on the cultivar Salinas were not easily differentiated from the symptoms observed on the noninoculated control treatments in the soilless assay, even at the highest inoculum concentration of $1 \times 10^{7} \mathrm{conidia} / \mathrm{ml}$. Comparison of the soilless growth chamber assay and a soil-based greenhouse assay revealed a significantly higher proportion of PI 251246 with root vascular discoloration in the soilless assay compared with the soil-based greenhouse assay $\left(\chi^{2}, 1 \mathrm{df}=8.9\right.$; $P=0.003$ ). There is thus an advantage to using the soilless growth chamber assay with PI 251246. Compared with the soil-based greenhouse assay, the soilless assay reduced the time required for evaluation of Verticillium wilt symptoms on lettuce from about 90 days to 42 days.
\end{abstract}

Verticillium wilt of lettuce (Lactuca sativa L.), caused by the fungus Verticillium dahliae Kleb., first appeared in coastal California in 1995 (22). This disease is difficult to control, principally because $V$. dahliae survives as microsclerotia in soil for up to 14 years (14), limiting the effectiveness of crop rotation. Additionally, $V$. dahliae is pathogenic on many crops grown in coastal California (5) and a number of weed species (24), all of which contribute to the survival and increase in population density of the pathogen in the soil. Because soil fumigation for Verticillium wilt of lettuce is cost-prohibitive, plant resistance offers the most practical long-term option for control.

Verticillium wilt symptoms on commercially available lettuce cultivars are most pronounced at market maturity, the phenological stage at which plants switch from vegetative growth to reproductive growth (bolting or seed stem production). $V$. dahliae infects lettuce plants through the roots; the vascular tissue then turns a characteristic brownish-black, and disease symptoms develop acropetally, with the lower leaves wilting and becoming chlorotic and necrotic before the upper

Corresponding author: Steven J. Klosterman

E-mail: Steve.Klosterman@ars.usda.gov

Accepted for publication 29 March 2009.

doi:10.1094/PDIS-93-7-0691

This article is in the public domain and not copyrightable. It may be freely reprinted with customary crediting of the source. The American Phytopathological Society, 2009. leaves (26). The production of a toxin may be responsible for the root discoloration and foliar symptoms in certain Verticillium spp.-plant interactions $(8,12-14)$, although vascular clogging also may give rise to these symptoms (14). Races of $V$. dahliae pathogenic on lettuce and tomato have been described $(2,9,25)$. Among the isolates of $V$. dahliae that can infect lettuce, race 1 strains cause symptoms on the cultivar Salinas but not on the cultivar La Brillante (25). In contrast, race 2 strains cause disease on both La Brillante and Salinas, and on all other lettuce cultivars and accessions that have been tested $(9,25)$.

The progression of Verticillium wilt symptoms has been linked to plant maturity in plant-Verticillium interactions. For example, the initiation of flowering appears to be a cue for the spread of cruciferous strains of $V$. dahliae in oilseed rape plants (28). Verticillium wilt symptoms on spinach and cauliflower occur after bolting or heading, respectively $(7,11)$. In an Arabidopsis-Verticillium pathosystem, symptom progression was demonstrated to be linked to the genetic control of plant development and lifespan (27). The Verticillium wilt-tolerant ecotype of Arabidopsis exhibited a pathogen-induced delay of early flowering, and the locus for this characteristic has been identified (27). In lettuce, resistant and susceptible cultivars are easily distinguishable at market maturity, but not prior to market maturity, suggesting that the progression of Verticillium wilt symptoms on lettuce is also dependent on plant maturity (9).

Conventional methods to examine Verticillium wilt on lettuce require a lengthy period before symptoms can be observed. Under greenhouse conditions, lettuce cultivars are evaluated for wilt symptom development at 90 to 110 days after seed germination (25). Root dips or soil drenches with conidial suspensions of $V$. dahliae are usually done in the initial 3 to 4 weeks, followed by transplantation and evaluation (25). These processes are laborintensive and costly in terms of both the amount of greenhouse space and time required. The ideal Verticillium wilt assay would entail less time to assess disease symptoms. Additionally, because transgenic isolates of $V$. dahliae may need to be evaluated, the ideal Verticillium wilt assay of lettuce would not require the collection of runoff water, nor would it require soil sterilization at the completion of the experiments.

The major objective of this study was to develop an in vitro soilless assay to examine pathogenicity and relative virulence of isolates of $V$. dahliae on lettuce. The lettuce line PI 251246 was selected for these experiments since this line flowers more quickly than many other lines. Early flowering lines produce flowers at approximately 45 to 65 days after planting, compared with 100 to 150 days for standard crisphead lettuce cultivars (16-18). This study demonstrated that the early flowering line PI 251246 can be used to reliably assess leaf and root symptoms of Verticillium wilt in a contained, soilless, growth chamber assay, thereby facilitating analyses of lettuce- $V$. dahliae interactions.

\section{MATERIALS AND METHODS}

Fungal strains and culture conditions. Isolates of $V$. dahliae used in this study included VdLs.16, VdLs.17, and VdLs.439 from lettuce (Lactuca sativa L.) and VdBob.70 from cauliflower (Brassica oleracea var. botrytis L.) $(15,26)$. VdLs.16 and VdLs.17 were isolated in 1996, VdLs.439 in 2001, and VdBob.70 in 1990, all from locations in California (15). The isolates of $V$. dahliae from lettuce are representative of race 1 (VdLs.16) and race 2 (VdLs.17, VdLs.439) (25). Long-term stocks of the fungal isolates were maintained at $-80^{\circ} \mathrm{C}$ in a $20 \%$ glycerol/potato dextrose broth ( $\mathrm{vol} / \mathrm{vol})$ suspension or in vials containing potato dextrose agar (PDA). Short-term stocks of the isolates were maintained as microsclerotia at $4^{\circ} \mathrm{C}$. The $V$. dahliae isolates were single-spored on PDA. The isolates were spread onto PDA plates with cotton swabs and grown for 3 to 4 days in the dark at $25^{\circ} \mathrm{C}$. All 
isolates produced darkly pigmented microsclerotia on PDA.

DNA sequences of the ribosomal RNA intergenic spacer (IGS) region of each isolate were compared with those previously submitted to the National Center for
Biotechnology Information (NCBI) (15) to verify the identity of each. Primers 034 (5'-GGGTCCTGTAAGCAGTAG-3') and 035 (5'-GAGCCATTCGCAGTTTCG-3') were used to amplify the IGS sequences by PCR (15). Reactions included 1× GoTaq
Flexi buffer (Promega, Madison, WI), 3 $\mathrm{mM} \mathrm{MgCl} 2,0.2 \mathrm{mM}$ dNTPs, $150 \mathrm{nM}$ of each of the primers 034 and 035, $20 \mathrm{ng}$ of DNA template, and 1.25 U of GoTaq Flexi DNA polymerase (Promega). Amplification was carried out in a PTC-200 DNA

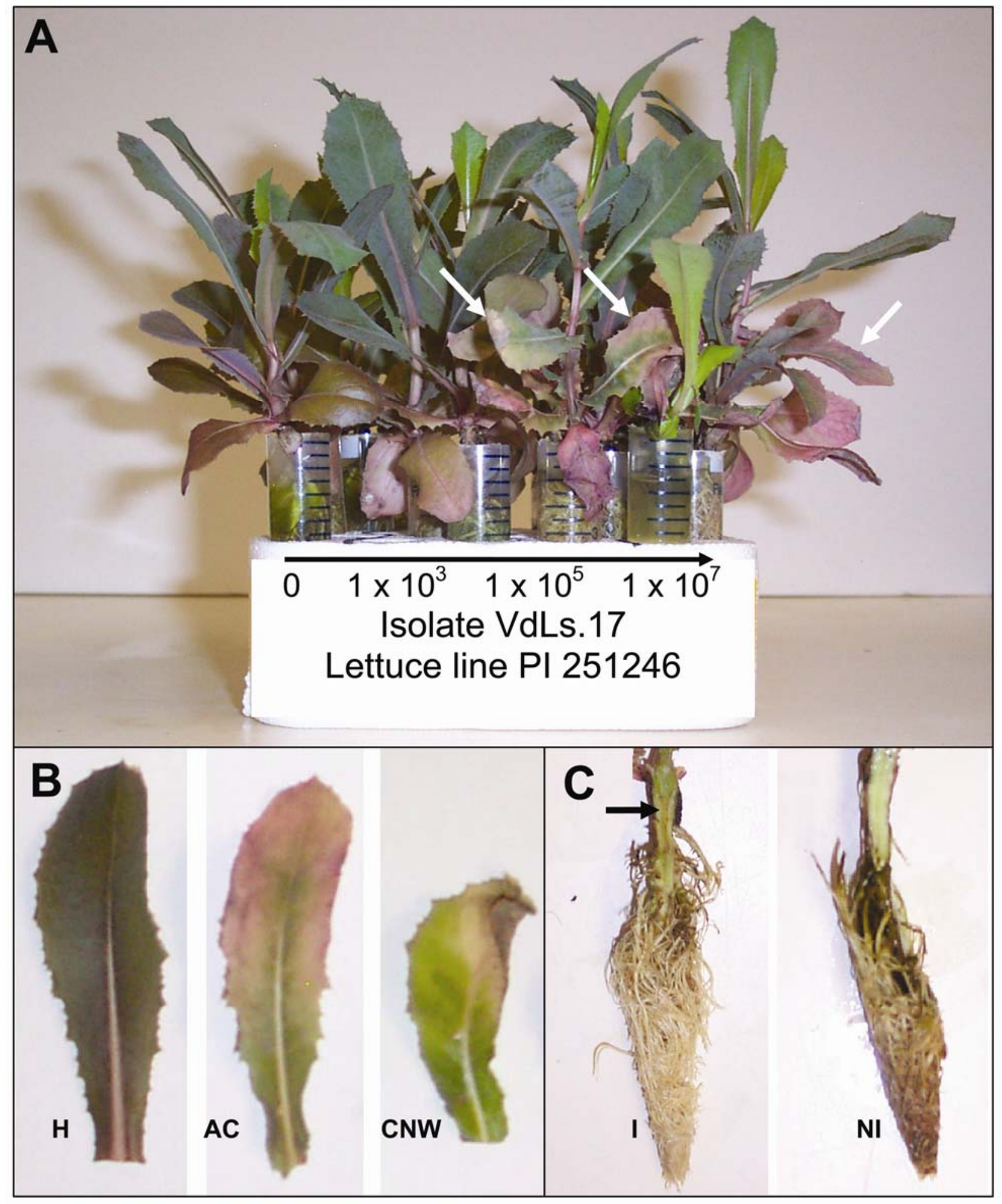

Fig. 1. A, Soilless assay for Verticillium wilt of lettuce using the early flowering line PI 251246. Conical Falcon tubes were placed in rows of four in a foaminsulated flat and inoculated with Verticillium dahliae at the inoculum concentrations shown. White arrows indicate leaves bearing symptoms of chlorosis and anthocyanin production. B, Representative healthy and symptomatic leaves of PI 2512463 weeks after inoculation with $V$. dahliae. Control leaf was excised from a water-treated control plant. Symptomatic leaves, excised from V. dahliae-inoculated plants, displayed increased anthocyanin production and chlorosis (AC); and chlorosis, necrosis, and wilting (CNW). C, Vascular discoloration of the taproot of PI 2512463 weeks after inoculation with V. dahliae. Black arrow indicates location of brown vascular discoloration in the inoculated (I) root system, while vascular discoloration was not observed in noninoculated (NI) root systems. 
Engine Cycler (MJ Research, Waltham, MA) programmed for $5 \mathrm{~min}$ at $94^{\circ} \mathrm{C}, 35$ cycles of $30 \mathrm{~s}$ at $94^{\circ} \mathrm{C}, 30 \mathrm{~s}$ at $51.5^{\circ} \mathrm{C}$, and $2 \mathrm{~min}$ at $72^{\circ} \mathrm{C}$, followed by $72^{\circ} \mathrm{C}$ for 10 min. The PCR products were cloned into vector pCR4.0-Topo (Invitrogen, Carlsbad, CA) and sequenced with universal primers T3 and T7 (Molecular Cloning Laboratories, San Francisco, CA). DNA sequences were analyzed using DNASIS MAX v2.9 (Hitachi Software Engineering America, Ltd., San Francisco, CA) and aligned with $V$. dahliae IGS sequences available in the NCBI database. The NCBI sequence accessions for the IGS regions of these isolates are DQ165209 (VdLs.16), DQ165210 (VdLs.17), DQ165219 (VdLs.439), and DQ165187 (VdBob.70).

Plant cultivars. The United States Department of Agriculture, Agricultural Research Service station in Salinas, CA provided seeds of the lettuce cultivar $\mathrm{La}$ Brillante, PI 251246, 81-1252-D-3-22M (abbreviated in this study as D-3-22), 811251-C-1M (C-1), 81-1252-C-1-11M (C1-11), and 81-1252-C-1-1M (C-1-1). Stocks of D-3-22, C-1, C-1-11, and C-1-1 have been characterized previously (18). Lines C-2-1-1 and C-2-1-11 are late flowering lines, while lines D-3-22 and C-1 are early flowering (18). Under long day conditions, early flowering lines begin flowering at 43 to 68 days after planting, whereas late flowering lines begin flowering at 98 to 143 days after planting (18). Seeds of cultivar Salinas were obtained from Pybas Seeds (Salinas, CA).

Soilless growth chamber assay for pathogenicity. To test the pathogenicity and relative virulence of $V$. dahliae, four isolates (VdLs.16, VdLs.17, VdLs.439, and VdBob.70) and a water control were used to examine symptom development on lettuce PI 251246 in a soilless growth chamber assay. Seeds of PI 251246 were planted in 200 wells in the seedling plug trays (Hummert Int., St. Louis, MO) with a pasteurized sand/potting soil $(3: 1)$ mixture and grown for 3 weeks in a Conviron E15 growth chamber (Controlled Environments Inc., Pembina, ND) set to a 16-h day/8-h night cycle at a constant temperature of $25^{\circ} \mathrm{C}$. The roots of seedlings at the fourleaf growth stage, approximately 3 weeks after planting the seed, were washed with tap water to remove debris, and the seedlings were placed upright into $6.5-\mathrm{ml}$ tubes (15-ml Falcon tubes cut to this length). Conidia of each of the isolates were scraped from 3- to 4-day-old culture plates into distilled water, and each was suspended in distilled water to a concentration of $1 \times 10^{7}$ conidia $/ \mathrm{ml}$. The plants in the 6.5-ml tubes were inoculated with each isolate using an automatic pipette by filling each tube with the appropriate conidial suspensions. Control plants received distilled water. The following day, the conidia were resuspended in the tubes using a separate pipette for each isolate, and the plants were arranged in a completely randomized design in a growth chamber. There were 10 replicate plants for each of the five treatments and a total of 50 plants per experiment. The experiment was conducted three times.

Because of the loss of water to transpiration and evaporation, approximately $5 \mathrm{ml}$ of water was added daily to each tube with an automatic pipette. Hoagland's nutrient solution (Phyto Technology Laboratories, Shawnee Mission, KS) was prepared with distilled water and added to each tube once each week in 5-ml aliquots. At the conclusion of each experiment, the tubes were immersed in $10 \%$ commercial bleach for at least $4 \mathrm{~h}$, rinsed with water, dried at room temperature, and reused in subsequent experiments.

In an initial experiment to test the early flowering line PI 251246 for reaction to Verticillium wilt, disease symptoms were apparent on the lower leaves 10 days after inoculation with $V$. dahliae (data not shown). By 2 weeks after inoculation, foliar symptoms were more pronounced and in general progressed in severity for up to 3 weeks. Thus, 3 weeks after inoculation was chosen for scoring symptomatic leaves of PI 251246 and other lettuce cultivars in this study. The early flowering lines D-3-22 and C-1 also were examined using the soilless assay, but these lines were difficult to score for leaf symptoms because of natural senescence of the lower leaves. Additionally, these two early flowering lines did not produce a robust taproot sufficient to evaluate root discoloration like that of PI 251246 in the soilless environment, so they were not selected for further use in this assay.

The PI 251246 plants were monitored daily for symptom development. Three weeks after inoculation, true leaves (approximately 10 leaves per plant) were rated as symptomatic or asymptomatic. Leaves were scored as symptomatic based on the appearance of one or more symptoms, such as uneven anthocyanin production or chlorosis, leaf curling, wrinkling, and necrosis (Fig. 1A and B). To examine root vascular discoloration, the taproot and crown were sliced longitudinally with a razor blade and scored as either positive or negative for root vascular discoloration (Fig. 1C). From each experiment, symptomatic leaf tissues from one plant, and leaf tissues from one control plant, were surface disinfested by immersing the tissue pieces in $10 \%$ commercial bleach for 1 min and plated on NP10 agar medium (20) to evaluate the presence or absence of $V$. dahliae.

The soilless assays for pathogenicity were analyzed using analysis of variance (ANOVA) statistics of ranked data using the PROC Mixed procedure of SAS (Version 9.1, SAS Institute, Cary, NC), with the LD_CI macro to generate relative effects (RE) for each treatment, and 95\% confidence intervals for detection of statistical differences between treatments $(6,19)$. For data analyses, leaf symptom data were expressed as the proportion of symptomatic leaves per plant, and the root vascular discoloration data were coded as 0 (no vascular discoloration) or 1 (vascular discoloration) for each plant. Each plant was treated as a separate replicate. Results from each experiment were consistent, and therefore the data from all three experiments were combined into a single analysis. The data were analyzed as a one-way ANOVA, with isolate as a fixed effect and experiment as a random effect. Three independent experiments were combined into a single analysis with experiment treated as a random variable. The median and maximum percentage of symptomatic leaves and the percentage of plants with root vascular discoloration were calculated for each isolate and cultivar.

Soilless assays to evaluate cultivars and inoculum concentrations. Experiments using the soilless growth chamber assay were conducted to evaluate PI 251246 for Verticillium wilt symptoms relative to two lettuce cultivars, La Brillante and Salinas. Three inoculum concentrations of race 1 and race $2 V$. dahliae were used in each of these soilless growth chamber assays and arranged in a split plot design, with each cultivar-by-isolate combination as a whole plot and inoculum concentration as a subplot. For each experiment, 16 plants of each cultivar were spaced in rows of four plants in a foam container: four plants for the water control treatment and four plants for each of the three inoculum concentration treatments. Three independent experiments were performed.

Leaf symptom and root discoloration data in the soilless assays in which cultivars and inoculum concentrations were evaluated as a split plot design using the GLIMMIX macro in SAS. To test for heterogeneity among the three independent experiments, a chi-square test for heterogeneity was conducted using the leaf symptom and root discoloration data. The results from each experiment were consistent, and therefore the data from all three experiments were combined into a single analysis. For the GLIMMIX data analyses, leaf symptoms were expressed as the proportion of symptomatic leaves in each of four plants and analyzed using a binomial distribution. Root discoloration data were expressed as the numbers of plants with root discoloration, and analyzed using a Poisson distribution. The GLIMMIX macro cannot handle values of zero. Therefore, a constant was added $(0.004$ for leaf symptom data and 0.1 for root discoloration data). Isolate, cultivar, concentration, and the resulting interactions were treated as fixed effects. Experiments and interactions with experiments were treated as random effects. Least-squares means and 
95\% confidence intervals were calculated for main effects and interactions to compare treatments. Data were reported as the percentage of symptomatic leaves and the number of plants with root vascular discoloration.

Greenhouse assay for pathogenicity. Greenhouse assays were conducted with isolate VdLs.17 of V. dahliae or distilled water as treatments for comparison with the soilless growth chamber assay and for comparisons of Verticillium wilt symptoms of PI 251246 with symptoms in other lettuce lines. The greenhouse experiments were conducted in a glass greenhouse at the USDA-ARS station in Salinas, CA, in June and July 2008. Fan-forced radiant heat was on below $18^{\circ} \mathrm{C}$ and an exhaust fan with evaporative cooling above $24^{\circ} \mathrm{C}$, although temperatures were recorded outside of this range in this greenhouse (15 to $41^{\circ} \mathrm{C}$ ). Seeds of lettuce lines PI 251246, D3-22, C-1, C-1-11, and C-1-1 were planted in 200 wells in seedling plug trays in a pasteurized sand/potting soil (3:1) mixture and grown for 3 weeks in a Conviron E15 growth chamber set to 16 -h day/8-h night cycles at a constant temperature of $25^{\circ} \mathrm{C}$. A soil drench of $3 \mathrm{ml}$ of $1 \times 10^{7}$ conidia $/ \mathrm{ml}$ of $V$. dahliae isolate VdLs.17 was applied to each seedling at 14 days and again at 20 to 21 days after planting. The soil drench technique of inoculating lettuce with $V$. dahliae has been used previously (25) and eliminates the need to blend inoculum into the soil mix for screening lettuce for Verticillium wilt resistance. One day following the second inoculation, the plants were transferred to $473.2 \mathrm{ml}(16 \mathrm{oz})$ foaminsulated cups containing a pasteurized sand/potting soil (3:1) mix in the greenhouse. There were 100 plants in each of three experiments: 10 inoculated plants of each of the five lettuce lines and 10 plants treated with water for each line. Plants were arranged in a completely randomized design. They were evaluated for symptoms 3 weeks after transferring to the greenhouse. The evaluation was done at 3 weeks to compare the timing of symptom devel- opment in the greenhouse assay with symptom development in the soilless growth chamber assay.

The greenhouse assays for pathogenicity were analyzed using analysis of variance (ANOVA) statistics of ranked data using the PROC Mixed procedure of SAS. The LD_CI macro generated relative effects (RE) for each treatment and 95\% confidence intervals for detection of statistical differences between treatments $(6,19)$. The results from each experiment were consistent, and therefore the data from all three experiments were combined into a single analysis. The greenhouse data were analyzed as a factorial experiment with treatment (water or isolate VdLs17 of V. dahliae), cultivar, and treatment-by-cultivar as fixed effects. To determine if disease incidence in the soilless growth chamber experiments was significantly greater than in greenhouse experiments, a chi-square statistic was calculated from a $2 \times 2$ contingency table formulated using data on the incidence of root discoloration of PI 251246 inoculated with VdLs.17 from the soilless assay with greenhouse assay pathogenicity experiments.

\section{RESULTS}

Soilless growth chamber assay for pathogenicity. Visual observations of leaves of PI 251246 inoculated with $V$. dahliae revealed irregular leaf chlorosis and anthocyanin production, in addition to leaf curling and wrinkling, within 3 weeks of inoculation (Fig. 1A and B). A single section of symptomatic leaf tissue of PI 251246 placed on NP10 medium enabled recovery of $V$. dahliae (data not shown). PI 251246 remained healthy in appearance for at least 3 weeks when treated with water instead of $V$. dahliae (0 in Fig. 1A), and the fungus was not recovered from sections of these plants (data not shown). Out of 438 plants in all six soilless experiments, three plants collapsed before disease symptoms were scored, so these plants were not used in the tabulation of the data sets because the presence or ab- sence of Verticillium wilt symptoms could not be determined.

Significant differences in the RE of percent symptomatic leaves were not detectable among the three lettuce isolates of $V$. dahliae inoculated onto PI 251246 (Table 1). Significant increases in the RE of percent symptomatic leaves were detected in all three of the lettuce isolates of $V$. dahliae $(\mathrm{RE} \geq 0.65)$ compared with the control treatment $(\mathrm{RE}=0.27)$ (Table 1$)$. In contrast, VdBob.70 $(\mathrm{RE}=0.25)$ did not cause a significant increase in the RE of percentage of symptomatic leaves when compared with the control plants (Table 1). Symptomatic leaves were recorded for both VdBob.70-inoculated and control plants, although at significantly lower levels than those plants inoculated with the lettuce isolates (Table 1). The median percentage of symptomatic leaves on plants inoculated with isolate VdLs.17 was $50 \%$, with a maximum of $78 \%$. The median percentage of symptomatic leaves for the control plants was 0 , with a maximum of $22 \%$ (Table 1).

Typical root vascular discoloration of PI 251246 caused by $V$. dahliae is depicted in Figure 1C. Root discoloration was observed in 80 to $83 \%$ of PI 251246 plants inoculated with the lettuce isolates, whereas none of the control plants or those inoculated with VdBob.70 developed vascular discoloration in the soilless assay (Table 1). There were no significant differences in RE estimates of root discoloration caused by the three lettuce isolates (Table 1). However, significantly higher RE estimates of root discoloration were observed for each of the lettuce isolates $(\mathrm{RE} \geq 0.65)$ compared with VdBob.70 $(\mathrm{RE}=0.25)$ and the control treatment $(\mathrm{RE}=0.25)($ Table 1$)$.

Soilless assays to evaluate cultivars and inoculum concentrations. At 3 weeks following inoculation, PI 251246, La Brillante, and Salinas varied significantly in the proportion of symptomatic leaves observed on plants inoculated with $V$. dahliae $(P=0.0005)$. Comparison of the percentage of symptomatic leaves among

Table 1. Percentage of symptomatic leaves and root vascular discoloration on lettuce line PI 2512463 weeks following inoculation with four isolates of Verticillium dahliae in a soilless growth chamber assay

\begin{tabular}{|c|c|c|c|c|c|c|c|c|c|}
\hline \multirow[b]{4}{*}{ Isolate ${ }^{c}$} & \multicolumn{5}{|c|}{ Percentage of symptomatic leaves ${ }^{a}$} & \multicolumn{4}{|c|}{ Root vascular discoloration ${ }^{\mathbf{a}}$} \\
\hline & \multirow[b]{3}{*}{ Med. } & \multirow[b]{3}{*}{ Max. } & \multicolumn{3}{|c|}{ Relative effect $^{b}$} & \multirow{3}{*}{$\begin{array}{c}\text { Percent } \\
\text { plants }\end{array}$} & \multicolumn{3}{|c|}{ Relative effect } \\
\hline & & & \multirow[b]{2}{*}{ Est. $^{d}$} & \multicolumn{2}{|c|}{$95 \% \mathrm{CI}$} & & \multirow[b]{2}{*}{ Est. } & \multicolumn{2}{|c|}{$95 \% \mathrm{CI}$} \\
\hline & & & & Lower & Upper & & & Lower & Upper \\
\hline VdLs.17 & 50 & 78 & 0.66 & 0.58 & 0.73 & 83 & 0.67 & 0.61 & 0.72 \\
\hline VdLs.16 & 47 & 80 & 0.65 & 0.56 & 0.72 & 80 & 0.65 & 0.59 & 0.71 \\
\hline VdLs.439 & 45 & 64 & 0.67 & 0.60 & 0.73 & 83 & 0.67 & 0.61 & 0.72 \\
\hline VdBob.70 & 0 & 20 & 0.25 & 0.21 & 0.29 & 0 & 0.25 & 0.23 & 0.28 \\
\hline Controle $^{\mathrm{e}}$ & 0 & 22 & 0.27 & 0.24 & 0.32 & 0 & 0.25 & 0.23 & 0.28 \\
\hline
\end{tabular}

a Percentage of symptomatic leaves and root vascular discoloration were calculated from a total of 30 plants for each isolate and the control treatment.

b The relative effect (RE) and 95\% confidence intervals were calculated from the analysis of rank values of the leaf symptom and root vascular discoloration data. Higher RE indicates a higher percentage of symptomatic leaves or higher percentage of plants with root vascular discoloration.

${ }^{c}$ Inoculum concentration for each isolate was $1 \times 10^{7}$ conidia $/ \mathrm{ml}$.

d Estimate.

e Distilled water. 
these cultivars revealed that PI 251246 had more disease than the other two cultivars in response to either $V$. dahliae isolate, VdLs.16 or VdLs.17 (Fig. 2). Significantly higher proportions of symptomatic leaves were observed on PI 251246 compared to La Brillante at the highest inoculum concentration $\left(1 \times 10^{7}\right.$ conidia/ml $)$ (Fig. 2D).

Inoculum concentration of $V$. dahliae had a significant effect on symptomatic leaves of the three cultivars $(P<0.0001)$ (Fig. 2). The effect of inoculum concentration on symptom development was most clearly apparent for PI 251246. Concentrations of $1 \times 10^{5}$ or $1 \times 10^{7}$ conidia $/ \mathrm{ml}$ of either the race 1 or race 2 isolates resulted in significantly more symptomatic leaves (Fig. 2C and D) than observed on the control plants (0 conidia/ml) (Fig. 2A). Inoculation of Salinas with $1 \times 10^{7}$ conidia $/ \mathrm{ml}$ of either isolate (Fig. 2D) resulted in significantly more symptomatic leaves than the control plants (Fig. 2A), but La Brillante displayed few foliar symptoms. Even at the highest inoculum concentration, the mean percentage of symptomatic leaves of cultivar La Brillante was approximately $6 \%$ (Fig 2D). Increasing inoculum concentrations also resulted in higher numbers of plants with root discoloration $(P<$ 0.0001). The effect of increasing inoculum concentration was more pronounced for PI 251246 than the other two cultivars; an inoculum concentration of $1 \times 10^{7} \mathrm{co}-$ nidia/ml of VdLs.16 and VdLs.17 caused root vascular discoloration in all of the PI 251246 plants in the three experiments shown in Table 2. Only La Brillante inoculated with VdLs.16 showed no differences for root discoloration with increasing inoculum concentration.

Cultivar-by-isolate interactions were evident in the root vascular discoloration data that were not apparent when evaluating leaf symptoms alone. The cultivar-byisolate interaction approached significance in the GLIMMIX analysis $(P=0.0586)$, and root discoloration data indicate that VdLs.16 is not pathogenic on La Brillante. The number of La Brillante plants with root vascular discoloration in the control treatment was not significantly different than inoculations with the VdLs.16 isolate of $V$. dahliae, at even the highest inoculum concentration (Table 2).

Greenhouse assay for pathogenicity. Three weeks after inoculation of C-1, C-21-1, C-2-1-11, D-3-22M, and PI 251246 plant lines, foliar symptoms were difficult to distinguish from senescing lower leaves in the greenhouse assay (data not shown). For this reason, only root vascular discoloration data were recorded in these greenhouse assays (Table 3 ). There was no significant difference in root vascular discoloration between PI 251246 and the other lettuce lines inoculated with isolate VdLs.17 in the greenhouse assay. In one of the lines, C-2-1-11, RE estimates of root discoloration for control plants $(\mathrm{RE}=0.43$,
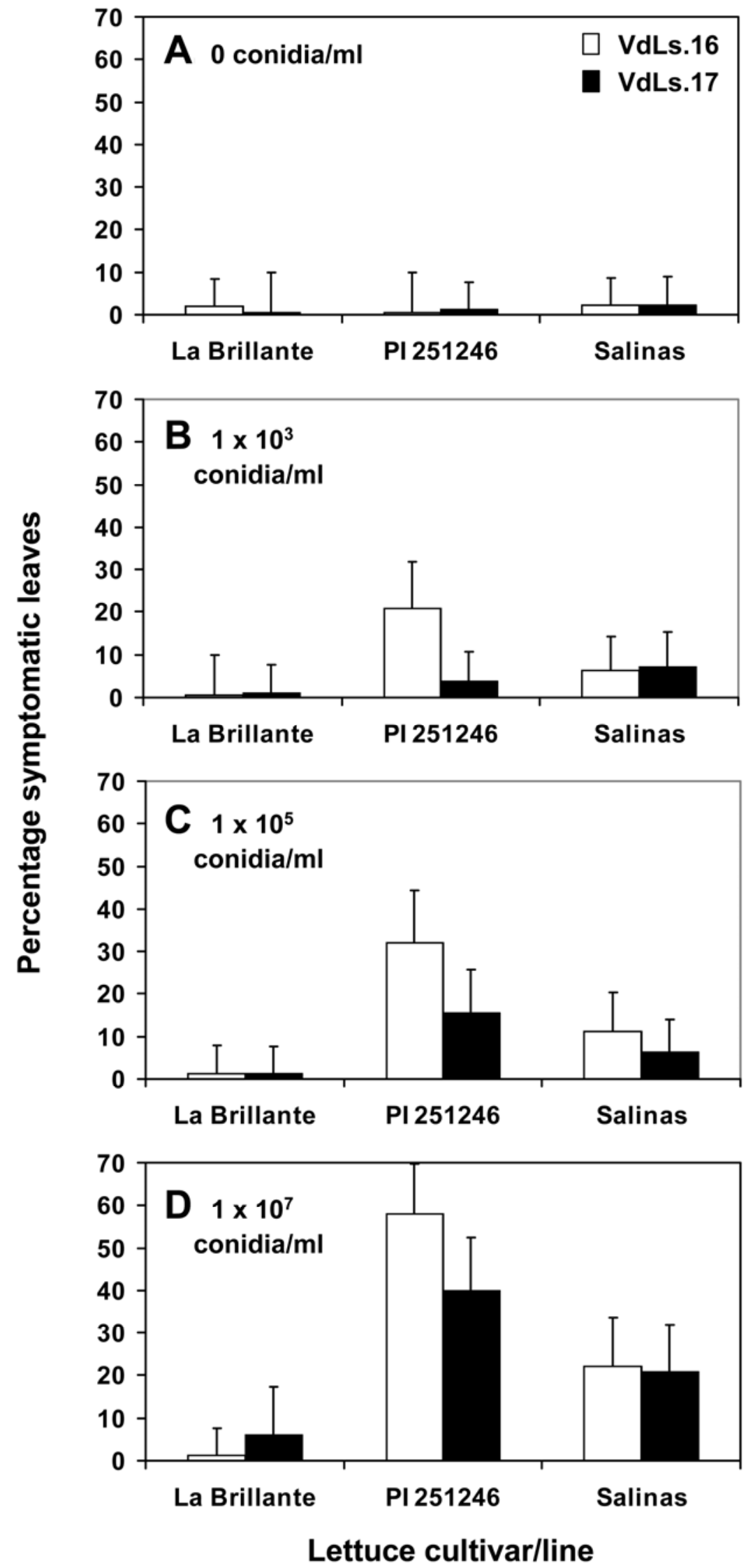

Fig. 2. Percentage of symptomatic leaves of lettuce cultivars 3 weeks following inoculation with Verticillium dahliae in a soilless growth chamber assay. Plants were either not inoculated (A) or inoculated with a range of concentrations of conidia of $V$. dahliae isolates VdLs.16 (race 1 on lettuce) and VdLs.17 (race 2 on lettuce) (B, C, D). Three independent factorial experiments were performed with three cultivars, two isolates, and four inoculum concentrations. (32 plants per cultivar, 48 plants per isolate, and 24 plants per concentration). Error bars represent 95\% confidence intervals. 
95\% CI $=0.39$ to 0.48 ) were not significantly different from the plants inoculated to 0.60 ) (Table 3). Comparison of the soilless assay and a soil-based greenhouse assay revealed a significantly higher proportion of PI 251246 with root vascular discoloration in the soilless assay com$\left(\chi^{2}, 1 \mathrm{df}=8.9 ; P=0.003\right)$. The percentage of PI 251246 plants that developed root symptoms in the soilless assays was never less than $83 \%$ across six experiments at the concentration of $1 \times 10^{7}$ conidia/ml of VdLs.17 (Tables 1 and 2), whereas the percentage of PI 251246 plants that develwith VdLs.17 $(\mathrm{RE}=0.52,95 \% \mathrm{CI}=0.44$ pared to the soil-based greenhouse assay

oped root symptoms in the greenhouse assays was never greater than $47 \%$ across three experiments (Table 3 ).

\section{DISCUSSION}

Development of Verticillium wilt symptoms is correlated with the onset of plant reproductive growth $(7,8,11,14,28)$. Because the early flowering lettuce line PI 251246 matures more quickly than most lettuce lines or cultivars, we hypothesized that PI 251246 would develop Verticillium wilt symptoms more quickly than other lettuce cultivars. The results of this study indicated that PI 251246 was well-suited to the soilless growth chamber assay devel-

Table 2. Root vascular discoloration ${ }^{\mathrm{a}}$ observed for three lettuce cultivars following inoculation with a range of different concentrations of each of two isolates of Verticillium dahliae in a soilless growth chamber assay

\begin{tabular}{lccccc}
\hline $\begin{array}{l}\text { Lettuce } \\
\text { cultivar/line }\end{array}$ & $\begin{array}{c}\text { Isolate of } \\
\text { V. dahliae }\end{array}$ & Concentration & Exp. 1 & Exp. 2 & Exp. 3 \\
\hline La Brillante & VdLs.16 & 0 & 0 & 0 & 0 \\
& & $1 \times 10^{3}$ & 0 & 0 & 0 \\
& & $1 \times 10^{5}$ & 0 & 0 & 0 \\
La Brillante & $1 \times 10^{7}$ & 0 & 0 & 0 \\
& VdLs.17 & 0 & 0 & 0 & 0 \\
& & $1 \times 10^{3}$ & 0 & 0 & 0 \\
PI 251246 & $1 \times 10^{5}$ & $0^{\mathrm{b}}$ & 0 & 1 \\
& & $1 \times 10^{7}$ & 2 & 2 & 2 \\
& & 0 & 0 & 0 & 0 \\
PI 251246 & $1 \times 10^{3}$ & $1^{\mathrm{b}}$ & 2 & 2 \\
& & $1 \times 10^{5}$ & $2^{\mathrm{b}}$ & 2 & 3 \\
\multirow{3}{*}{ Salinas } & $1 \times 10^{7}$ & 4 & 4 & 4 \\
& & 0 & 0 & 0 & 0 \\
& & $1 \times 10^{3}$ & 1 & 0 & 0 \\
SdLs.17 & $1 \times 10^{5}$ & 2 & 0 & 2 \\
& & $1 \times 10^{7}$ & 4 & 4 & 4 \\
& & 0 & 0 & 0 & 0 \\
& & $1 \times 10^{3}$ & 0 & 0 & 0 \\
& & $1 \times 10^{5}$ & 1 & 0 & 0 \\
& & $1 \times 10^{7}$ & 2 & 1 & 2 \\
& & 0 & 0 & 0 & 0 \\
& & $1 \times 10^{3}$ & 1 & 0 & 0 \\
& & $1 \times 10^{5}$ & 0 & 0 & 1 \\
& & $1 \times 10^{7}$ & 3 & 0 & 0 \\
\hline
\end{tabular}

a Root discoloration scored on a 0 to 4 scale, based on the number of four plants inoculated that displayed root vascular discoloration.

${ }^{b}$ Only three plants total were scored for vascular discoloration due to death of the fourth plant from causes other than Verticillium wilt.

Table 3. Root vascular discoloration ${ }^{\mathrm{a}}$ of five lettuce lines inoculated with isolate VdLs.17 of Verticillium dahliae and grown in greenhouse conditions

\begin{tabular}{llcccc}
\hline & & & \multicolumn{3}{c}{ Relative effect $^{\mathbf{b}}$} \\
\cline { 4 - 6 } Lettuce line & Inoculation & treatment $^{\mathbf{c}}$ & $\begin{array}{l}\text { Percent plants with root } \\
\text { vascular discoloration }\end{array}$ & & \multicolumn{3}{c}{$\mathbf{9 5 \%}$ CI } \\
\cline { 4 - 6 } & Estimate & Lower & Upper \\
\hline D-3-22M & Water & 3.3 & 0.42 & 0.38 & 0.45 \\
D-3-22M & VdLs.17 & 40.0 & 0.60 & 0.51 & 0.68 \\
PI 251246 & Water & 0 & 0.40 & 0.38 & 0.42 \\
PI 251246 & VdLs.17 & 47.0 & 0.63 & 0.54 & 0.71 \\
C-1 & Water & 0 & 0.40 & 0.38 & 0.42 \\
C-1 & VdLs.17 & 47.0 & 0.63 & 0.54 & 0.71 \\
C-2-1-1 & Water & 0 & 0.40 & 0.38 & 0.42 \\
C-2-1-1 & VdLs.17 & 33.0 & 0.57 & 0.49 & 0.65 \\
C-2-1-11 & Water & 6.6 & 0.43 & 0.39 & 0.48 \\
C-2-1-11 & VdLs.17 & 23.0 & 0.52 & 0.44 & 0.60 \\
\hline
\end{tabular}

a Root discoloration on 30 plants per treatment.

${ }^{\mathrm{b}}$ The relative effect (RE) and $95 \%$ confidence intervals were calculated from the analysis of rank values of the root vascular discoloration data. The higher RE, the higher the percentage of plants with root vascular discoloration.

${ }^{c}$ Two inoculations using $1 \times 10^{7}$ conidia/ml (see Materials and Methods). oped to rapidly assess wilt development in lettuce, thus potentially accelerating analyses of lettuce- $V$. dahliae interactions.

Greenhouse analyses for Verticillium wilt of lettuce, using standard crisphead cultivars, may take 90 to 110 days to complete (25), whereas the time from planting to the scoring of leaf symptoms was 35 to 42 days using PI 251246 in the soilless growth chamber assay developed in this study. Some leaves were recorded as symptomatic on the noninoculated PI 251246 control plants. For those noninoculated PI 251246 plants where symptomatic leaves were recorded, the maximum percentage of symptomatic leaves on a plant was $22 \%$, and none of these plants had root vascular discoloration. In contrast, all PI 251246 plants with $>22 \%$ symptomatic leaves developed root vascular discoloration. Therefore, discriminating between symptomatic and nonsymptomatic plants can be done by observing leaf symptoms.

The high inoculum pressure and environmental conditions in the soilless growth chamber assay likely contributed to the higher numbers of PI 251246 plants with wilt symptoms. There was a significant increase in the percentage of symptomatic leaves at the inoculum concentration of $1 \times$ $10^{7}$ on PI 251246 , and the devised tube assay ensured that the inoculum load was in constant association with the roots. Although the effects of environmental conditions were not assessed in this study, moisture level, $\mathrm{pH}$, photoperiod, and temperature are all critical factors in Verticillium wilt development (14). Temperatures of 22 to $27^{\circ} \mathrm{C}$ are optimal for growth of $V$. dahliae (14), and symptom development may be limited outside of this range. For example, severe Verticillium wilt symptoms were apparent on cotton grown in controlled environment chambers at air temperatures of $26^{\circ} \mathrm{C}$ day $/ 20^{\circ} \mathrm{C}$ night, but not at $33^{\circ} \mathrm{C}$ day $/ 26^{\circ} \mathrm{C}$ night cycles, whether inoculated with nondefoliating or defoliating strains of $V$. dahliae (23). Unlike leaf tissues from $26^{\circ} \mathrm{C}$ day $/ 20^{\circ} \mathrm{C}$ night cycles, $V$. dahliae was recovered only rarely from the leaf tissues of cotton plants grown at $33^{\circ} \mathrm{C}$, indicating that pathogen growth was suppressed in those plants grown at $33^{\circ} \mathrm{C}(23)$. The variability in greenhouse temperatures in this study may have had an adverse effect on the pathogen, thereby limiting symptom development. Air temperatures in the range of 15 to $41^{\circ} \mathrm{C}$ have been recorded in the greenhouse in which this study was conducted.

The results indicate that PI 251246 is susceptible to both races 1 and 2 of $V$. dahliae and, therefore, is not useful to differentiate between races of the pathogen on lettuce. La Brillante is resistant to race 1 and susceptible to race 2 of $V$. dahliae $(9,25)$. Therefore, a significant increase in root vascular discoloration or foliar symptoms on $\mathrm{La}$ Brillante inoculated with VdLs.16 (race 1) was not observed. The 
highest inoculum concentration of VdLs.17, the race 2 isolate, did result in $50 \%$ of La Brillante plants with root vascular discoloration. In contrast, Salinas is susceptible to both race 1 and race 2 isolates of $V$. dahliae $(9,25)$. In this study, Salinas was susceptible to both VdLs.16 and VdLs. 17 as expected.

The results of this study indicate a significant link between the numbers of infected plants and inoculum concentration of $V$. dahliae. Overall, disease symptoms increased with increasing inoculum concentration on PI 251246. Significant root vascular discoloration and foliar symptoms were observed on PI 251246 at $1 \times 10^{7}$ conidia/ml for both lettuce isolates of $V$. dahliae, VdLs.16 and VdLs.17. However, the cauliflower isolate VdBob.70 did not cause root or foliar symptoms at $1 \times 10^{7}$ conidia/ml in the soilless growth chamber assay. This substantiates the results of previous greenhouse studies, in which isolate VdBob.70 did not cause wilt symptoms on lettuce $(15,26)$. Taken together, these results indicate an optimal concentration of $1 \times 10^{7}$ conidia/ml in the soilless growth chamber assay. The concentration of $1 \times 10^{7}$ conidia/ml will be applied in future analyses of pathogenicity of $\mathrm{V}$. dahliae using PI 251246 in the soilless assay.

Assays and inoculation techniques have been described that allow efficient screening for Verticillium wilt resistance in alfalfa, strawberry, horseradish, and rapeseed plants $(1,3,4,10,21)$. The results of this study revealed that the soilless growth chamber assay described does not appear to be useful for screening lettuce cultivars for resistance to Verticillium wilt or for differentiating races of $V$. dahliae on lettuce. There was high variation in the numbers of plants of Salinas and La Brillante that developed root and foliar symptoms. These crisphead lettuce cultivars developed more senescent lower leaves than PI 251246 that were difficult to discriminate from symptomatic leaves. Also, Salinas, La Brillante, and early flowering lines evaluated (D-3-22 and C-1) did not exhibit as robust a growth as PI 251246 in the soilless assay.

The soilless growth chamber assay has several advantages over greenhouse assays to assess Verticillium wilt symptoms in lettuce. Most importantly, the soilless growth chamber assay provides a rapid measure of foliar symptoms. The time required to observe symptoms from planting was reduced by about 7 weeks compared to the greenhouse assay, and the soilless assay did not require a substantial investment of labor to maintain the plants. Additionally, the assay was reliable with PI 251246. Root vascular discoloration was observed on all of the PI 251246 plants that displayed $>22 \%$ symptomatic leaves. The relationship between root vascular discoloration and the percentage of symptomatic leaves was less apparent in cultivars Salinas and La Brillante, in which foliar symptom development was not obvious in some instances because of the common occurrence of senescent lower leaves in these cultivars. Therefore, the combination of percent symptomatic leaves and root vascular discoloration data both provide measures of Verticillium wilt on PI 251246. Another advantage is that the soilless assay is contained in a growth chamber, limiting transfer of the fungus outside of the laboratory and growth chamber. This enables a more appropriate and convenient assay for working with transgenic fungi, for which containment procedures are necessary.

There are some potential drawbacks associated with the soilless assay described in this study. First, daily watering of the plants over a 3-week period is essential, as water is lost in the tubes overnight and must be replaced the following day. On younger seedlings, excess water is detrimental to their development. While developing this assay, 1-week-old seedlings of PI 251246 with more limited root systems also were tested. These plants grew too slowly and many collapsed in the tubes. Second, the build-up of algae in some tubes, particularly 2 to 3 weeks after setting up the tubes, was a concern. But this apparently did not cause symptom development on PI 251246 plants because algal growth also was observed on some roots of the control plants.

In summary, using the soilless growth chamber assay, the early flowering lettuce line PI 251246 displayed foliar wilt symptoms and root vascular discoloration 3 weeks after inoculation with race 1 and race 2 isolates of $V$. dahliae. In contrast, a conventional greenhouse assay was ineffective for consistent measurement of Verticillium wilt symptoms on lettuce 3 weeks postinoculation, supporting the need for a more reliable and rapid assay. This study demonstrated the utility of PI 251246 and the soilless growth chamber assay developed to quickly assess pathogenicity or relative virulence of isolates of $V$. dahliae. In addition to uses mentioned above, inoculations of PI 251246 in the soilless environment can be useful to quickly pass strains through the plant. Leaves that are symptomatic can be plated and the strains of $V$. dahliae can be collected. Further studies are underway to develop a race 1-resistant early flowering line by breeding resistance from La Brillante into PI 251246. The use of the soilless assay with this race 1resistant line may allow rapid differentiation of race 1 and race 2 of $V$. dahliae.

\section{ACKNOWLEDGMENTS}

We thank Krishna V. Subbarao for reviewing the manuscript and Gary E. Vallad for helpful discussions. We also thank Amy Anchieta for technical assistance.

\section{LITERATURE CITED}

1. Acharya, S. N., and Huang, H.-C. 2003. Breeding alfalfa for resistance to Verticillium wilt: A sound strategy. Pages $345-371$ in: Advances in Plant Disease Management. H.-C Huang and S. N. Acharya, eds. Research Signpost, Trivandrum, Kerala, India.

2. Alexander, L. J. 1962. Susceptibility of certain Verticillium-resistant tomato varieties to an Ohio isolate of the pathogen. Phytopathology 52:998-1000.

3. Atibalentja, N., and Eastburn, D. M. 1997 Evaluation of inoculation methods for screening horseradish cultivars for resistance to Verticillium dahliae. Plant Dis. 81:356-362.

4. Aubury, R. G., and Rogers, H. H. 1969. The determination of resistance to Verticillium wilt (V. albo-atrum) in lucerne. J. Br. Grassland Soc. 24:235-237.

5. Bhat, R. G., and Subbarao, K. V. 1999. Host range specificity in Verticillium dahliae. Phytopathology 89:1218-1225.

6. Brunner, E., Domhof, S., and Langer, F. 2002 Nonparametric Analysis of Longitudinal Data in Factorial Experiments. John Wiley \& Sons, New York.

7. du Toit, L. J., Derie, M. L., and HernandezPerez, P. 2005. Verticillium wilt in spinach seed production. Plant Dis. 89:4-11.

8. Fradin, E. F., and Thomma, B. P. H. J. 2006 Physiology and molecular aspects of Verticillium wilt diseases caused by $V$. dahliae and $V$. albo-atrum. Mol. Plant Pathol. 7:71-86.

9. Hayes, R. J., Vallad, G. E., Qin, Q.-M., Grube, R. C., and Subbarao, K. V. 2007. Variation for resistance to Verticillium wilt in lettuce ( $\mathrm{Lac}$ tuca sativa L.). Plant Dis. 91:439-445.

10. Jordan, V. W. L. 1973. A procedure for the rapid screening of strawberry seedlings for resistance to Verticillium wilt. Euphytica 22:367372.

11. Koike, S. T., Subbarao, K. V., Davis, R. M., Gordon, T. R., and Hubbard, J. C. 1994. Verticillium wilt of cauliflower in California. Plant Dis. 78:1116-1121.

12. Nachmias, A., Buchner, V., and Burstein, Y. 1985. Biological and immunochemical characterization of a low molecular weight phytotoxin isolated from a protein-lipopolysaccharide complex produced by a potato isolate of Verticillium dahliae Kleb. Physiol. Plant Pathol. 26:43-55.

13. Palmer, C. S., Saleeba, J. A., and Lyon, B. R. 2006. Phytotoxicity on cotton ex-plants of an $18.5 \mathrm{kDa}$ protein from culture filtrates of Verticillium dahliae. Physiol. Mol. Plant Pathol. 67:308-318.

14. Pegg, G. F., and Brady, B. L. 2002. Verticillium Wilts. CABI Publishing, Wallingford, UK.

15. Qin, Q.-M., Vallad, G. E., Wu, B. M., and Subbarao, K. V. 2006. Phylogenetic analyses of phytopathogenic isolates of Verticillium spp. Phytopathology 96:582-592.

16. Ryder, E. J. 1985. Use of early flowering genes to reduce generation time in backcrossing, with specific application to lettuce breeding. J. Am. Soc. Hortic. Sci. 110:570-573.

17. Ryder, E. J. 1988. Early flowering in lettuce as influenced by a second flowering time gene and seasonal variation. J. Am. Soc. Hortic. Sci. 113:456-460.

18. Ryder, E. J. 1996. Ten lettuce genetic stocks with early flowering genes Ef-1ef-1 and Ef-2ef2. HortScience 31:473-475.

19. Shah, D. A., and Madden, L. V. 2004. Nonparametric analysis of ordinal data in designed factorial experiments. Phytopathology 94:3343.

20. Sorensen L. H., Schneider, A. T., and Davis, J. R. 1991. Influence of sodium polygalacturonate sources and improved recovery of Verticillium spp. from soil. (Abstr.) Phytopathology 81:1347.

21. Steventon, L. A., Happstadius, I., Okori, P., and Dixelius, C. 2002. Development of a rapid technique for the evaluation of the response of 
Brassica napus to Verticillium wilt. Plant Dis. 86:854-858.

22. Subbarao, K. V., Hubbard, J. C., Greathead, A. S., and Spencer, G. A. 1997. Verticillium wilt. Pages 26-27 in: Compendium of Lettuce Diseases. R. M. Davis, K. V. Subbarao, R. N. Raid, and E. A. Kurtz, eds. American Phytopathological Society, St. Paul, MN.

23. Temple, S. H., DeVay, J. E., and Forrester, L. L. 1973. Temperature effects upon development and pathogenicity of defoliating and nondefoliating pathotypes of Verticillium dahliae in leaves of cotton plants. Phytopathology
63:953-958.

24. Vallad, G. E., Bhat, R. G., Koike, S. T., Ryder, E. J., and Subbarao, K. V. 2005. Weedborne reservoirs and seed transmission of Verticillium dahliae in lettuce. Plant Dis. 89:317-324.

25. Vallad, G. E., Qin, Q.-M., Grube, R., Hayes, R. J., and Subbarao, K. V. 2006. Characterization of race-specific interactions among isolates of Verticillium dahliae pathogenic on lettuce. Phytopathology 96:1380-1387.

26. Vallad, G. E., and Subbarao, K. V. 2008. Colonization of resistant and susceptible lettuce cultivars by a green fluorescent protein-tagged isolate of Verticillium dahliae. Phytopathology 98:871-885.

27. Veronese, P., Narasimhan, M. L., Stevenson, R. A., Zhu, J.-K., Weller, S. C., Subbarao, K V., and Bressan, R. A. 2003. Identification of a locus controlling Verticillium disease symptom response in Arabidopsis thaliana. Plant J. 35:574-587.

28. Zhou, L., Hu, Q., Johansson, A., and Dixelius C. 2006. Verticillium longisporum and V. dahliae: Infection and disease in Brassica napus. Plant Pathol. 55:137-144. 